Revue

Revue de l'histoire des religions

de Ihistoire des religions

3 | 2013

Varia

\title{
Marianne CARBONNIER-BURKARD, Calvin : une vie
}

Paris, Desclée de Brouwer, 2009, 160 p., $21 \mathrm{~cm}, 16 €$, ISBN

978-2-220-06117-7.

Nicolas Piqué

URL : http://journals.openedition.org/rhr/8151

DOI : $10.4000 /$ rhr.815

ISSN : 2105-2573

Éditeur

Armand Colin

Édition imprimée

Date de publication : 1 septembre 2013

Pagination : 422-423

ISBN : $978-2200928650$

ISSN : 0035-1423

Référence électronique

Nicolas Piqué, «Marianne carbonnier-burkard, Calvin : une vie », Revue de l'histoire des religions [En ligne], 3 | 2013, mis en ligne le 08 octobre 2013, consulté le 22 septembre 2020. URL : http:// journals.openedition.org/rhr/8151 ; DOI : https://doi.org/10.4000/rhr.8151

Ce document a été généré automatiquement le 22 septembre 2020.

Tous droits réservés 


\section{Marianne CARBONNIER-BURKARD, Calvin: une vie}

Paris, Desclée de Brouwer, 2009, 160 p., $21 \mathrm{~cm}, 16 €$, ISBN

978-2-220-06117-7.

Nicolas Piqué

\section{RÉFÉRENCE}

Marianne CARBONNIER-BURKARD, Calvin : une vie, Paris, Desclée de Brouwer, 2009, 160 p., $21 \mathrm{~cm}, 16 €$, ISBN 978-2-220-06117-7.

1 Cette biographie prend place dans le cadre de l'année anniversaire 2009, Calvin étant né en 1509. Découpant sa vie en différentes périodes, inégales quant à l'importance des sources (Calvin avant Calvin jusqu'à l'exil, l'appelé, le réformateur, l'exilé et la mort de Calvin), M. Carbonnier-Burkard croise évidemment les sources (Vie de Calvin de T. de Bèze notamment, mais aussi, et de façon plus nouvelle, les divers Registres genevois, Registre de la compagnie des pasteurs, du Conseil de Genève, du Consistoire de Genève, les deux derniers parus récemment et largement exploités ici), sans oublier les acquis des travaux plus spécialisés. L'intérêt de cette biographie réside donc dans ce caractère synthétique, proposant de façon claire, informée et relativement concise un portrait du réformateur de Genève.

2 Le texte est par ailleurs accompagné d'encarts proposant soit des synthèses souvent utiles (précisant des points historiques, par exemple l'organisation du Consistoire à Genève, ou des questions plus doctrinales, comme le sens de la prédestination), soit des extraits de textes de Calvin venant éclairer opportunément le propos biographique. M. Carbonnier-Burkard, cela mérite d'être souligné, présente la vie de Calvin en reconstituant de manière claire les enjeux de ses positions théologiques, y compris dans leur élaboration avant l'installation définitive à Genève, tout en analysant les effets sociaux et politiques de ce positionnement théologique. On prendra ici deux exemples pour illustrer cette analyse contextualisée. Le premier a trait à l'affaire 
Servet, cet adversaire de Calvin, mis à mort à Genève en 1553. M. Carbonnier-Burkard reconstitue clairement à la fois les enjeux doctrinaux mais aussi l'intrication entre le procès intenté à Servet et les relations compliquées, à cette même époque, entre Calvin et le Conseil (au sein duquel des familles genevoises influentes contestent la discipline sur laquelle veille le Consistoire selon des principes calviniens). L'exploitation du Registre du Consistoire permet également de souligner la sévérité de la police ecclésiastique lorsque la position de Calvin sera assurée, instaurant une discipline austère, tout en relevant l'évolution de la séparation entre les compétences du Consistoire et celles du Conseil, mettant à mal, s'il en était besoin, le mythe d'une théocratie genevoise.

Il faut également signaler l'intérêt du chapitre consacré à «L'exilé du royaume ". M. Carbonnier-Burkard y étudie l'attention jamais démentie de Calvin pour la situation française. 1555 figure une date charnière, entre l'époque où n'existent en France que des « Églises plantées », et celle des «Églises dressées » (c'est-à-dire caractérisées par la discipline et le ministère de la parole, voir p. 108 et suivantes) ; ce moment correspond également, à Genève, à l'élection de syndics favorables à Calvin, désormais en mesure de s'occuper davantage de la situation des réformés en France. Ce chapitre est également l'occasion de mieux comprendre la conception calvinienne du droit de résistance, appelé à jouer un rôle important à la fin du siècle. M. Carbonnier-Burkard présente précisément les efforts de Calvin, à l'époque de la conjuration d'Amboise, pour faire appel aux princes de sang (comme Antoine de Bourbon ou Louis de Condé). Jamais les simples fidèles seuls n'auront été poussés par Calvin à se révolter. Ce livre contribue donc utilement à une connaissance précise de Calvin, en dépassant les archétypes et les simplifications.

\section{AUTEURS}

\section{NICOLAS PIQUÉ}

Université de Grenoble 1. 